\title{
Casos notificados de eventos adversos pós-vacinação: contribuição para o cuidar em enfermagem
}

\author{
Reported cases of adverse events following immunization: contribution to nursing care \\ Casos notificados de eventos adversos por vacunación: contribución a los cuidados de \\ enfermería
}

\author{
Nathalya Macedo Nascimento Costa ; Ana Maria Machado Leão ${ }^{I I}$
}

\begin{abstract}
RESUMO: Este estudo objetivou caracterizar a população atingida pelos eventos adversos pós-vacinação - segundo o sexo, idade, identificação das vacinas - e analisar os eventos. Trata-se de uma pesquisa documental com abordagem quantitativa. A coleta dos dados ocorreu em 2014, mediante observação de fichas de notificação pós-vacinação, no período de 2010 a 2013, em dois centros municipais de saúde, situados no Município do Rio de Janeiro. Foram analisadas 214 fichas com 329 eventos adversos. Os resultados mostram que o sexo feminino e a faixa etária menor de um ano foram os mais acometidos. As vacinas que mais produziram eventos adversos foram constituídas pelo adjuvante hidróxido de alumínio, sendo a Tetravalente a com o maior percentual. Os eventos adversos mais frequentes foram os leves e moderados. Conclui-se que o enfermeiro, responsável pela imunização, deve ter conhecimento dos imunobiológicos e dos seus eventos adversos para preveni-los.

Palavras-Chave: Vacinação; vigilância epidemiológica; notificação; enfermagem.
\end{abstract}

\begin{abstract}
This quantitative, documentary study aimed to characterize the population affected by post-vaccination adverse events, by sex, age, and the vaccines, and to analyze the events. Data on 329 post-vaccination adverse events was collected in 2014 from 214 notification records completed in 2010-2013 at two municipal health centers in the Rio de Janeiro municipal area. The results show that females and under one year-olds were the most affected. The vaccines that produced most adverse events comprised the adjuvant aluminum hydroxide, with the Tetravalent formulation returning the highest percentage. The most frequent adverse events were mild to moderate. It was concluded that nurses responsible for immunization should have a knowledge of immunobiologics and related adverse events in order to prevent them.

Keywords: Vaccination; epidemiological surveillance; notification; nursing.
\end{abstract}

RESUMEN: Este estudio tuvo como objetivo caracterizar a la población afectada por los eventos adversos por vacunación, según el sexo, la edad, la identificación de las vacunas y también analizar los acontecimientos. Se trata de una investigación documental con abordaje cuantitativo. La recolección de datos ocurrió en 2014, a través de observación de registros de notificación de eventos adversos por vacunación, en el período 2010-2013, en dos unidades de salud, ubicadas en el Municipio de Río de Janeiro. Se han analizado 214 registros de notificación con 329 eventos adversos. Los resultados muestran que las mujeres y los niños con menos de un año de edad fueron los más afectados. Las vacunas que han ocasionado mayor número de eventos adversos tenían en su composición el adyuvante hidróxido de aluminio, siendo que Tetravalente aparecía con el porcentaje más alto. Los eventos adversos más frecuentes fueron los leves y moderados. Se concluye que el enfermero, responsable por la inmunización, debe tener conocimiento sobre los inmunobiológicos y sus eventos adversos para poder prevenirlos. Palabras-Clave: Vacunación; vigilancia epidemiológica; notificación; enfermería.

\section{INTRODUÇÃO}

Com o desenvolvimento e descoberta das primeiras vacinas, na tentativa de controlar as doenças infecciosas, a imunização era uma prática obrigatória, gerando repugnância e conflitos da população como a revolta da vacina. Não se pode confirmar se os imunobiológicos estavam totalmente livres de riscos, mas exigiam dos profissionais coragem para o desenvolvimento das atividades vacinais. Durante a década de 1980 e 1990, ocorre queda da incidência das doenças imunopreviníveis graças ao esclarecimento da população e profissionais de saúde sobre a segurança das vacinas ${ }^{\text {III }}$, no entanto com o crescente número de doses aplicadas surge o medo dos eventos adversos pós-vacinação ${ }^{1,2}$.

A vacina é um produto imunobiológico constituído por um ou mais agentes imunizantes sob diversas formas: bactérias vivas atenuadas, bactérias mortas ou avirulentas, componentes de bactérias,

'Enfermeira Graduada pela Faculdade de Enfermagem da Universidade do Estado do Rio de Janeiro, Brasil. E-mail: nathmacedo2010@hotmail.com. "Enfermeira, Mestre, Professora Assistente do Departamento de Enfermagem em Saúde Pública da Faculdade de Enfermagem da Universidade do Estado do Rio de Janeiro. Brasil. E-mail: ammleao@gmail.com.

IIIEsta pesquisa recebeu o Prêmio Rachel Haddock Lobo, $2^{\circ}$ lugar, no $7^{\circ}$ Simpósio Nacional - O Cuidar em Saúde e Enfermagem, Universidade do Estado Rio de Janeiro, 2014. 
toxinas obtidas em cultura de bactérias, vírus vivo atenuado, vírus inativado e fração de vírus. Além disso, agentes imunizantes possuem também outros componentes como: líquido de suspensão constituído por água destilada e soro fisiológico; conservantes; estabilizadores e antibióticos para evitar o crescimento de contaminantes e adjuvantes aumentando o poder imunogênico da vacina ${ }^{3}$.

Os eventos adversos pós-vacinação podem ser entendidos como qualquer sinal ou sintoma grave, indesejável ou inesperado, manifestado em um indivíduo que tenha recebido algum imunobiológico. Podem ser classificados quanto à causa: induzido pela vacina, devido ao seu componente; erros relacionados à técnica de preparação, manipulação ou administração; e coincidente, ou seja, o evento já existia no momento da vacinação, mas só se manifestou depois da aplicação do produto. Dessa forma, dependendo da intensidade e das manifestações ocorridas, os casos suspeitos de eventos adversos pós-vacinação devem ser investigados e notificados ${ }^{2-4}$.

Nesse contexto, surge o problema de pesquisa: Quais as características dos eventos adversos pósvacinação no período 2010 - 2013, notificados nos centros municipais de saúde?

Destaca-se alta frequência de eventos adversos locais e sistêmicos leves, estando a vigilância epidemiológica voltada para os eventos moderados e graves ${ }^{2-4}$.

O interesse por essa temática emergiu da vivência das autoras no Projeto de Extensão Vacinando a Comunidade, da Faculdade de Enfermagem do Estado do Rio de Janeiro (ENF/UERJ). Durante um período de 24 meses, observou-se que o levantamento do histórico vacinal das pessoas durante a triagem, a técnica correta na preparação e aplicação dos imunobiológicos e as orientações no momento pós-vacinação são de suma importância para evitar os eventos adversos.

A partir dessa perspectiva, o estudo torna-se relevante, pelo conhecimento dos eventos adversos pósvacinais registrados e das características da população acometida, visando à atuação segura do enfermeiro e à prevenção de eventos.

Diante dessas considerações, propôs-se, como objetivos da pesquisa, caracterizar a população atingida pelos eventos adversos pós-vacinação segundo o sexo e a idade, identificar as vacinas e analisar os eventos adversos pós-vacinação.

\section{REVISÃo DE LITERATURA}

O Programa Nacional de Imunização (PNI) contribui para o controle das doenças imunopreviníveis, mediante a administração de imunizantes nas unidades de saúde e campanhas. Visando manter as elevadas coberturas vacinais e seguranças dos imunobiológicos, o PNI implantou, em 1991, o Sistema de Vigilância Epidemiológica de Eventos Adversos pós-vacinação (SVEAPV), um dos mais bem-sucedidos, que pretende notificar, investigar, acompanhar e padronizar condutas adequadas diante das ocorrências ${ }^{1}$.

Com o surgimento do SVEAPV, os profissionais de saúde que trabalhavam nos postos de saúde tiveram que ser treinados a respeito do diagnóstico e conduta, possibilitando um maior entendimento dos eventos pós-vacinação 5 .

Após a manifestação do evento adverso, o profissional de saúde deve anotar os dados da pessoa que recebeu o imunobiológico e suas manifestações na ficha de notificação específica. Após seu preenchimento, deverá ser encaminhada para a Vigilância Epidemiológica, instância local ou municipal, no período de até 48 horas, considerando, assim, que a investigação foi iniciada em tempo oportuno. Quando os eventos são graves, devem ser notificados ao nível hierárquico superior imediatamente, com a finalidade de alertar a vigilância e obter orientações quanto à investigação, se necessária ${ }^{3,4,6,7}$.

O enfermeiro responsável pela sala de imunização deve ter conhecimento sobre os imunobiológicos, assim como os eventos que podem ocasionar, coordenando a equipe de enfermagem sob sua supervisão para as ações de imunização. Estudo adverte quanto à incipiência do conhecimento profissional sobre tal temática, refletindo sobre a tomada de decisão e as lacunas na investigação dos eventos adversos pósvacinação, que caracterizam risco ao cliente. $\mathrm{O}$ que se observa é que o enfermeiro só se limita aos registros desses eventos em nível local, repassando-os para a vigilância epidemiológica ${ }^{2}$.

\section{Metodologia}

Trata-se de um estudo descritivo, documental com abordagem quantitativa, realizado em dois centros municipais de saúde, localizados no Município do Rio de Janeiro. As unidades prestam serviço de atenção primária, que abrangem a promoção, proteção da saúde, prevenção de agravos, diagnóstico, tratamento, reabilitação e manutenção da saúde. Além disso, possuem o setor de epidemiologia, responsável por investigar os casos suspeitos notificados, repassandoos para a instância municipal. As duas unidades são de fácil acesso e servem de campo de estágio para os alunos de graduação da ENF/UERJ.

Após a aprovação pelo Comitê de Ética em pesquisa da UERJ, com o parecer $n^{\circ} 642.374$, procedeu-se à coleta de dados nas fichas de notificação de eventos adversos pós-vacinais, pois estas devem registrar as informações do paciente sobre suas reações adversas ao imunobiológico. Os eventos adversos selecionados ocorreram no período de 2010 a 2013, conforme os registros de 216 fichas de notificação, as quais representaram a 
amostra. Entretanto, duas tinham preenchimento incompleto no campo da idade e foram excluídas. Assim, a amostra foi reduzida para 214 fichas.

O trabalho foi desenvolvido em conformidade com a Resolução n 466/2012 do Conselho Nacional de Saúde ${ }^{8}$.

A coleta de dados ocorreu em maio de 2014, tendo sido utilizado um formulário semiestruturado, com quatro perguntas, das quais uma aberta e três fechadas.

Para compor o estudo, foram selecionadas as seguintes variáveis: sexo, idade, as vacinas e os eventos adversos pós-vacinação.

Os dados de 2011 a 2013 foram coletados no setor de epidemiologia do Centro de Saúde Maria Augusta Estrella (CMS-MAE), obtendo-se 149 fichas. Vale destacar que não foi possível localizar as fichas de 2010 nessa unidade; as fichas foram recolhidas e enviadas para a Secretaria de Saúde. No Centro Municipal de Saúde Milton Fontes Magarão (CMS-MFM), as 65 fichas impressas não estavam arquivadas; houve mudança organizacional das notificações, que passaram a ser online. Portanto, os dados de 2010 do CMS-MAE e de todo período selecionado do CMS-MFM foram coletados na Secretaria Municipal de Saúde e Defesa Civil do Estado do Rio de Janeiro. Foram utilizados o programa Epi-Info e as fichas de notificação de eventos adversos.

Foram selecionados os seguintes critérios para exclusão do estudo: fichas de notificação dos eventos fora do período selecionado, fichas preenchidas com caligrafia ilegível e com dados incompletos.

A análise utilizou o programa Microsoft Office Excel 2007 para a tabulação e a organização dos achados, permitindo sintetizá-los em tabelas, conforme a estatística descritiva. A discussão dos achados foi realizada com base na literatura.

\section{Resultados e Discussão}

Na amostra selecionada, o sexo feminino predominou, com 130 (61\%) sujeitos, enquanto o masculino apresentou 84 (39\%). Existe baixa procura dos serviços de saúde por homens, podendo estar relacionada a fatores socioculturais; já as mulheres são as maiores usuárias do serviço ${ }^{9}$. Porém, não há relação direta com os achados deste trabalho, visto que a faixa etária com mais eventos incidiu sobre os menores de um ano. No total de fichas analisadas, ocorreram 329 eventos adversos, classificados como leve, moderado e grave, evidenciando mais de um evento em certas fichas. Os eventos adversos são classificados conforme a intensidade: grave, quando ocorre hospitalização por no mínimo 24 horas, acarretando risco de óbito; moderado, necessita de avaliação, exames complementares e tratamento médico; leve, quando não necessita de tratamento médico e nem de exames complementares, sendo este último caracterizado como prática da enfermagem ${ }^{1,2,4,5}$.
A distribuição das notificações por faixa etária, nas duas unidades, apresentou maior incidência de eventos adversos pós-vacinação na faixa etária de menores de um ano - 136 (64\%); já os de 5 a 12 anos atingiram 7 (3\%), com menor incidência, segundo a Tabela 1 . As mais vulneráveis são as crianças menores de um ano, por terem o sistema imunológico imaturo e devido à quantidade de vacinas aplicadas em várias doses, nesse segmento etário, conforme preconizado pelo $\mathrm{PNI}^{1,6}$.

TABELA 1: Distribuição das notificações dos eventos adversos por faixa etária dos Centros Municipais de Saúde Milton Fontes Magarão e Maria Augusta Estrella. Rio de Janeiro, 2010 a 2013. $(\mathrm{N}=214)$

\begin{tabular}{lcc}
\hline \multicolumn{1}{c}{ Faixa etária } & f & $\%$ \\
\hline$<1$ ano & 136 & 64 \\
1 a 4 anos & 20 & 9 \\
5 a 12 anos & 7 & 3 \\
$>12$ anos & 51 & 24 \\
\hline
\end{tabular}

Foram administrados 214 imunobiológicos que acarretaram eventos adversos, levantados nas fichas de notificação, conforme dispõe a Tabela 2 .

TABELA 2: Distribuição das vacinas administradas que causaram eventos adversos notificados pelos Centros Municipais de Saúde Milton Fontes Magarão e Maria Augusta Estrella. Rio de Janeiro, 2010 a 2013. $(N=214)$

\begin{tabular}{lcc}
\hline \multicolumn{1}{c}{ Vacinas } & $\mathrm{f}$ & $\%$ \\
\hline Tetravalente & 52 & 24,2 \\
dT & 26 & 12,1 \\
Pentavalente & 22 & 10,2 \\
BCG & 22 & 10,2 \\
DTP & 19 & 8,9 \\
VIP & 15 & 7,0 \\
Influenza & 11 & 5,1 \\
Antirrábica & 9 & 4,2 \\
Hepatite b & 8 & 3,8 \\
Tríplice Viral & 6 & 2,9 \\
Rotavírus & 6 & 2,9 \\
Pneumocócica 10 - valente & 5 & 2,3 \\
Meningocócica C & 4 & 1,9 \\
Febre Amarela & 4 & 1,9 \\
Soro Antirrábico & 2 & 1,0 \\
Varicela & 2 & 1,0 \\
VOP & 1 & 0,4 \\
\hline
\end{tabular}

A Tetravalente, contra difteria, tétano e pertussis (coqueluche), combinada (DPT) com a vacina Haemophilus influenzae tipo b, apresentou alta incidência de eventos adversos, quando comparada às outras vacinas administradas. Tais reações são justificadas pelo adjuvante hidróxido de alumínio, componente encontrado em vários imunobiológicos, como a Meningocócica C, 
Dupla adulto, contra difteria e tétano (dT), Pentavalente (DTP + Hepatite B e meningite causados pelo Haemophilus Influenzae tipo b), Tríplice bacteriana, contra difteria, tétano e pertussis (DTP) e Hepatite B; estas possuem, também, como conservante, o timerosal, com exceção da vacina Meningocócica C.

Indivíduos com alergia cutânea ao timerosal podem apresentar processo inflamatório local. Nessa situação, a vacina não é contraindicada ${ }^{7}$. A vacina Pneumocócica 10 valente é constituída de 10 sorotipos de pneumocócicos, conjugada com a proteína D de Haemophilus Influenzae e carreada de toxoide diftérico e tetânico e composta de fosfato de alumínio e cloreto de sódio ${ }^{10}$.

Os imunobiológicos com hidróxido de alumínio podem ocasionar eventos locais de inflamação, estimulando o sistema imunológico, e com doses subsequentes podem aumentar o número de manifestações. Para evitar as reações locais, é de grande importância realizar movimentos rotativos do frasco da vacina para a homogeneização da solução antes de aspirar cada dose, o líquido administrado deve ser introduzido lentamente e o posicionamento deve ser seguro e confortável, especialmente em criança a ser vacinada ${ }^{11}$.

A vacina Tetravalente é indicada para crianças a partir de dois meses, com esquema de três doses aos dois, quatro e seis meses, reforço aos 15 meses com a vacina DTP. Além do hidróxido de alumínio como adjuvante, contém também o componente pertussis, que pode ocasionar eventos adversos. Vacinas com esse componente apresentam eventos adversos com pouca gravidade, geralmente, nas primeiras 48 horas $^{5,11,12}$.

A BGC teve 22 (10,2\%) notificações, foi a quarta vacina que mais ocasionou eventos adversos, igualmente à Pentavalente. Geralmente, os eventos adversos da vacina BCG estão relacionados, principalmente, a erros de técnica, dose acima do volume adequado, aplicação profunda por via subcutânea, contaminação no momento da preparação, conservação inadequada do produto. Esse imunobiológico é uma suspensão de bactéria viva atenuada contra a tuberculose, que provoca eventos após a vacinação, como a evolução de um nódulo local, que progride para pústula, seguida de crosta e úlcera, com duração de seis a 10 semanas, originando uma cicatriz. Tais eventos devem ser esclarecidos aos responsáveis pela criança para que fiquem atentos aos eventos inesperados que possam ocorrer ${ }^{7,13}$.

É necessário que o enfermeiro tenha conhecimento e destreza quanto à aplicação dessa vacina, por via intradérmica, possibilitando que essa habilidade seja adquirida por outros profissionais, mediante capacitação, para evitar erros de técnicas e assegurar ao vacinado um cuidado livre de danos ${ }^{13}$.

A vacina inativada injetável contra a poliomielite (VIP) apresentou somente 15 (7\%) eventos adversos. Este dado corrobora outro estudo, que ressalta a ocorrência de apenas reações locais ${ }^{14}$.
As reações de hipersensibilidade são alérgicas e podem estar relacionadas à composição de vacinas cultivadas em ovos embrionados de galinha, porém são as que oferecem imunidade duradoura com dose única, pela constituição de vírus vivo; algumas têm potencial para causar eventos adversos mais graves, como as vacinas Tríplice Viral, Febre Amarela, Influenza e Antirrábica. As duas últimas vacinas citadas são inativadas, contêm vírus mortos e exigem mais de uma dose, podendo ocasionar eventos adversos relacionados à hiperimunidade com doses exageradas ${ }^{7}$. Este estudo aponta reação de hipersensibilidade após duas horas da administração da vacina Antirrábica e urticária generalizada e após a aplicação da vacina contra Febre Amarela; já a vacina Tríplice viral e Influenza não manifestaram reação anafilática a ovo de galinha.

A oral contra a Poliomielite (VOP) revelou 1 $(0,3 \%)$ notificação e a contra Varicela, 2 (0,6\%). As duas vacinas são constituídas de vírus vivos atenuados e o Soro Antirrábico é composto de imunoglobulinas, como fenol, timerosal ou tricresol (conservantes) e cloreto de sódio (solvente), seus eventos adversos ocorrem entre seis e 12 dias $^{7}$. Esses três imunobiológicos causaram poucos eventos, nesta pesquisa, apresentando manifestações locais como mialgia, após a vacina contra a varicela, exantema, prurido, hipersensibilidade, depois do Soro Antirrábico e febre, no caso da VOP.

A oral contra o Rotavírus é uma vacina elaborada com vírus isolados de humanos e atenuados. Os eventos adversos registrados foram resultantes da aplicação, concomitante ou não, de outras vacinas? Foram notificados os eventos de fezes com raias de sangue e cianose. Outros estudos ressaltam os eventos adversos graves desse imunobiológico, como a obstrução intestinal; devido ao processo isquêmico, pode ocorrer presença de sangue nas fezes, nos casos mais graves. Destaca-se a importância da aplicação do imunobiológico em crianças até 24 meses, que previne a invaginação intestinal; se aplicada fora do período preconizado, aumenta o risco do evento ${ }^{5,15}$.

Nota-se a alta frequência de vacinas, constituídas de hidróxido de alumínio, que ocasionaram eventos adversos, como reações locais. Nesses casos, são recomendadas mais de uma dose. Outro percentual significativo refere-se às vacinas de vírus vivo como Tríplice Viral e Febre Amarela.

Devem ser levadas em consideração as contraindicações para a administração das vacinas, como nos casos de portadores de imunodeficiência congênita ou adquirida, uso de corticoides com esquema imunodepressor, portadores de neoplasia maligna, uso de quimioterapia e radioterapia. Existem também as falsas contraindicações, como diarreia leve ou moderada, afecções alérgicas das vias respiratórias, doença de pele, desnutrição, internação hospitalar, que acarretam prejuízo na cobertura vacinal, devido à falta de informação dos vacinados. Deve-se adiar a administração 
de vacinas vivas virais nos casos de indivíduos com doença febril grave, transplante de medula, uso de imunoglobulinas e tratamento com doses baixas de corticoides ${ }^{3,7,16}$.

Dos 329 eventos adversos, as reações locais foram as mais significativas, como dor, rubor calor, enduração, edema e eritema, sendo frequentes em quase todas as vacinas, exceto pelas orais como VOP e Rotavírus. A vacina $B C G$ não apresentou eventos como dor, rubor e calor. $\mathrm{O}$ exantema foi revelado pelas vacinas Antirrábica, Pneumocócicas, Tríplice Viral, DTP e Tetravalente. Na vacina Tríplice viral, o exantema está associado aos componentes contra o sarampo e a rubéola ${ }^{7}$. A conduta adotada para as reações locais é manter o esquema vacinal ${ }^{6}$. Ver Tabela 3.

A irritação local e lesão muscular são provocadas pela introdução errada da agulha. É recomendado o uso de agulhas longas para atingir o tecido muscular, pois quando a administração ocorre no tecido subcutâneo poderá ocasionar irritação, inflamação ou necrose local ${ }^{7,11,12}$.

O nódulo pode aparecer no local da aplicação, sendo absorvido, lentamente, durante semanas? ${ }^{7}$. As vacinas que apresentaram nódulo, como eventos adversos, foram a Tetravalente, BCG, Meningocócica C, Pneumocócica 10 - valente, Hepatite B, e Pentavalente.

A administração de antígenos ocasiona uma reação fisiológica, elevando a temperatura axilar, maior ou menor que $39^{\circ} \mathrm{C}$; outras ocorrências são os abscessos locais, devido à reação inflamatória ${ }^{2,7}$. As vacinas que causaram febre, neste estudo, foram a Tetravalente, Pentavalente, DTP, dT, Hepatite b, Antirrábica, Tríplice Viral, VOP, Meningocócica C, Pneumocócica 10 - Valente, Influenza e Rotavírus. O abscesso quente foi registrado em 10 (3\%) notificações e foram ocasionados pelas vacinas BCG, dT, Tetravalente e Pentavalente. Tais eventos sugerem infecção secundária ${ }^{2,7}$. O abscesso frio, com 3 (0,9\%) notificações, ocorreu após a Pentavalente e a DTP; foi explicado pela inoculação inadequada, na via subcutânea, quando deveria ser intramuscular, caracterizando um erro de técnica ${ }^{7}$. Baseado nos achados, nota-se que os dois eventos caracterizam erros de técnica realizada pelo profissional, destacando a infecção secundária como o mais frequente.

A vacina $B C G$ apresentou abscesso com drenagem espontânea, conforme 3 (0,9\%) notificações, indicando sinais inflamatórios localizados e 1 (0,3\%) com linfadenopatia regional supurada. Tais achados indicam técnica incorreta no momento da aplicação ${ }^{3}$. A BCG, Influenza, dT e Tríplice Viral apresentaram linfadenopatia regional não supurada -13 (4\%). Deve-se acompanhar esse evento até o seu desaparecimento, geralmente em quatro meses ${ }^{1}$. A linfadenopatia decorrente da aplicação da vacina Tríplice Viral é associada ao componente rubéola?.
TABELA 3: Distribuição de eventos adversos notificados dos Centros Municipais de Saúde Milton Fontes Magarão e Maria Augusta Estrella. Rio de Janeiro, 2010 a 2013. ( $N=329)$

\begin{tabular}{|c|c|c|}
\hline Eventos Adversos & $f$ & $\%$ \\
\hline Dor, rubor, calor & 63 & 19.1 \\
\hline Nódulo & 36 & 11,0 \\
\hline Enduração & 35 & 10.7 \\
\hline Edema & 29 & 8,9 \\
\hline Febre Menor que $39^{\circ} \mathrm{C}$ & 29 & 8,9 \\
\hline Linfadenopatia não supurada & 13 & 4,0 \\
\hline Abscesso quente & 10 & 3,0 \\
\hline Febre maior ou igual a $39^{\circ} \mathrm{C}$ & 10 & 3,0 \\
\hline Outros locais & 10 & 3 \\
\hline Exantema & 9 & 2,8 \\
\hline Eritema & 9 & 2,8 \\
\hline Episódio hipotônico hiporresponsivo & 7 & 2,1 \\
\hline Convulsão febril & 5 & 1,5 \\
\hline Cefaleia & 5 & 1,5 \\
\hline Palidez & 4 & 1,2 \\
\hline Hipersensibilidade após 2 horas & 4 & 1,2 \\
\hline Abscesso com drenagem espontânea & 3 & 0,9 \\
\hline Abscesso frio & 3 & 0,9 \\
\hline Choro persistente & 3 & 0,9 \\
\hline Febre não aferida & 3 & 0,9 \\
\hline Hematomas & 3 & 0,9 \\
\hline Hipotonia & 3 & 0,9 \\
\hline Artralgia & 3 & 0,9 \\
\hline Prurido local & 3 & 0,9 \\
\hline Letargia & 2 & 0,6 \\
\hline Celulite & 2 & 0.6 \\
\hline Mialgia & 2 & 0,6 \\
\hline Fezes com raias de sangue & 2 & 0,6 \\
\hline Prostração & 2 & 0,6 \\
\hline Angiodema de membros & 2 & 0,6 \\
\hline Linfadenopatia regional supurada & 1 & 0,3 \\
\hline Linfonodomegalia axilar D & 1 & 0,3 \\
\hline Taquicardia & 1 & 0,3 \\
\hline Taquipneia & 1 & 0,3 \\
\hline Náusea & 1 & 0,3 \\
\hline Síndrome Guillain Barré & 1 & 0,3 \\
\hline Diarreia & 1 & 0,3 \\
\hline Vômito & 1 & 0,3 \\
\hline Cianose & 1 & 0,3 \\
\hline Doença do sono & 1 & 0,3 \\
\hline Equimose & 1 & 0,3 \\
\hline Sonolência & 1 & 0,3 \\
\hline Não responde a estímulos & 1 & 0,3 \\
\hline Irritabilidade & 1 & 0,3 \\
\hline Urticária generalizada & 1 & 0,3 \\
\hline
\end{tabular}

A conduta frente aos eventos adversos determina o tratamento com analgésico, no caso de dor, compressas frias nas primeiras 24-48 horas após a aplicação e, no caso de abscessos, devem encaminhar o cliente para avaliação médica?

A qualificação do enfermeiro na sala de vacinação é de grande importância, pois ele deve seguir as normas estabelecidas pelo PNI, possuindo conheci- 
mento adequado dos eventos adversos pós- vacinação e sua prevenção, o qual deve ser repassado para outros profissionais por meio de ações de capacitação ${ }^{4}$.

Alguns eventos graves apresentam-se, neste estudo, como o episódio hipotônico hiporresponsivo $(\mathrm{EHH})$, cuja característica clínica surge nas primeiras 48 horas após a aplicação da vacina, podendo durar minutos ou dias, seguido de palidez, desaparecimento do tônus muscular e ausência de resposta a estímulos. A maioria das crianças segue com irritabilidade e febre ${ }^{6}$. As vacinas que apresentaram o EHH foram a Tetravalente, a DTP e a Pneumocócica 10 - valente. Estudo aponta a DTP e a Tetravalente associadas ao EHH, devido ao seu componente coqueluche (pertussis); também ocorrem casos em outras vacinas como a pneumocócica?

A convulsão febril foi registrada em 5 (1,5\%) notificações; apresenta-se nas primeiras 72 horas após a aplicação da vacina. $O$ choro persistente aparece, geralmente, nas primeiras 24 horas, não havendo explicação fisiopatológica. As vacinas que proporcionaram esses eventos foram a Tetravalente e a Pentavalente. A febre maior que $39^{\circ} \mathrm{C}$ indica risco de convulsão ${ }^{7}$. A administração de altas concentrações de toxoide tetânico pode ocasionar irritabilidade ${ }^{7}$. A irritabilidade decorrente da vacina dT foi mencionada em 1 (0,3\%) notificação. Tal evento está relacionado à alta quantidade de doses administradas ou ao erro de técnica.

As reações de hipersensibilidade foram provocadas pelas vacinas Tetravalente, soro Antirrábico e Pneumocócica 10 - valente. Segundo o Ministério da Saúde, ainda não foi possível relacionar a hipersensibilidade com algum componente da vacina Tetravalente ${ }^{7}$. O Soro Antirrábico pode apresentar a doença do soro, que é uma reação de hipersensibilidade, acompanhada de febre, manifestação cutânea, articular e linfoganglionar, que ocorre devido ao depósito de imunocomplexos nos vasos sanguíneos ${ }^{10}$. Houve, também, mialgia após a vacina contra a Febre Amarela. Em outro estudo, não foi descrita a mialgia como evento decorrente da aplicação dessa mesma vacina $^{7}$. A hipersensibilidade ocorreu também na Influenza; o evento é mais frequente em indivíduos que nunca receberam doses anteriores ${ }^{17}$.

A Meningocócica $\mathrm{C}$ conjugada provocou, como eventos adversos, a diarreia e vômito; nos protocolos oficiais, não há justificativa para a causa desses eventos. Nas notificações levantadas, o Soro Antirrábico apresentou prurido. Este dado corrobora um estudo que descreveu tal evento como uma das manifestações cutâneas?

Alguns achados nesta pesquisa não estão descritos nos protocolos do Ministério da Saúde, como a taquicardia e a taquipneia, ocasionadas pela vacina DPT; a falta de resposta a estímulo, após administração da vacina Hepatite B; angioedema de membros, devido à vacina Pentavalente; equimose, na vacina Antirrábi- ca; letargia, na vacina Hepatite B e DTP; prostração pela dT e Hepatite B, celulite na DTP e dT; artralgia, caracterizada por dor articular na DTP; prurido, na Influenza e dT; palidez, nas vacinas BCG, Rotavírus e DTP; hematoma, nas vacinas VIP, Antirrábica e Pentavalente; e cefaleia, na vacina Pneumocócica e dT.

Outro evento grave, com porcentagem não muito significativa, foi a Síndrome de Guillain Barré (SGB), com apenas $1(0,3 \%)$ notificação, ocasionado pela Influenza. Este achado caracteriza comprometimento do sistema nervoso periférico, levando a graus variados de fraqueza motora, podendo atingir os membros superiores e a face. Essa síndrome é associada à vacina Influenza, desde o primeiro aparecimento em 1976. Cabe ressaltar, que o próprio Vírus da Influenza pode desencadear a SGB, mas não é muito frequente ${ }^{18}$.

\section{CONClUSÃo}

Embora os imunobiológicos possam ocasionar eventos adversos pós-vacinação, devido aos seus componentes, erros de técnica ou características do próprio vacinado, vale ressaltar que a vacinação é de grande importância para a prevenção de doenças infecciosas, significando benefício para a população.

O sexo feminino apresentou maior incidência de eventos adversos, a faixa etária menor de um ano foi a mais acometida por sua imaturidade imunológica e a coincidência com o período que recebe maior quantidade de vacinas, de acordo com o PNI.

A vacina Tetravalente foi a que mais produziu eventos adversos - destacando-se as reações locais pelo fato deste imunobiológico ser constituído pelo adjuvante hidróxido de alumínio, que também é encontrado em várias vacinas.

Com relação à vacina $\mathrm{BCG}$, os erros de técnica foram os mais ressaltados. Esta pesquisa apresentou uma amostra reduzida, referente a duas unidades de saúde, o que significou uma limitação do estudo, que requer reaplicação. Espera-se que este estudo possa colaborar na elaboração de outros trabalhos científicos e favorecer a assistência de enfermagem, a partir das reflexões sobre mudanças no cuidar, pois o enfermeiro tem um papel fundamental no Programa Nacional de Imunização e na vigilância das reações pós-vacinais.

\section{REFERÊNCIAS}

1.Araújo TME, Carvalho PMG, Vieira RDF. Análise dos eventos adversos pós-vacinais ocorridos em Teresina. Rev Bras Enferm. 2007; 60:444-8.

2.Bissetto LHL, Cubas MR, Malucelli A. A prática de enferagm frente aos eventos adversos pós- vacinação. Rev esc enferm USP. 2011; 45:1128-34

3.Ministério da Saúde (Br). Manual de normas de vacinação. Brasília (DF): Secretaria de Comunicação; 2001. 
4.Alves H, Domingos LMG. Manejo de eventos adversos pós vacinação pela equipe de enfermagem: desafio para o cuidado. Rev enferm UERJ. 2013; 21: 502-7.

5.Martins RM, Maia, MLS. Eventos adversos pós- vacinais e resposta social. Hist ciêc saúde. 2003; 10: 807-25. 6.Piacentini S, Moreno LC. Eventos adversos pós vacinais no município de Campo Grande (MS, Brasil). Ciênc saúde coletiva. 2011; 16: 531-6.

7.Ministério da Saúde (Br). Secretaria de Vigilância em Saúde. Departamento de Vigilância Epidemiológica. Manual de vigilância epidemiológica de eventos adversos pós - vacinação. Brasília (DF): Editora MS; 2008.

8.Ministério da Saúde (Br). Conselho Nacional de Saúde. Que define as Normas reguladoras de pesquisa envolvendo seres humanos: Resolução no 466/2012. Brasília (DF): Fundação Oswaldo Cruz; 2013.

9.Campos EC, Sudan LCP, Mattos EDM, Fidelis R. Fatores relacionados à vacinação contra a gripe em idosos: estudo transversal, Cambé, Paraná, Brasil. Cad Saúde Publica. 2012; 28: 878-88.

10.Ministério da Saúde $(\mathrm{Br})$. Proposta para Introdução da Vacina Pneumocócica 10 - Valente (conjugada) no calendário básico de vacina da criança. Brasília (DF):Editora MS; 2010.

11.Jesus DM, Bastos MA, Carvalho EC. Estudo dos eventos adversos provocados pela vacina tetravalente.
Rev enferm UERJ. 2004; 12: 299 -305.

12.Freitas FRM, Saton HK, Aranda BAF, Pacheco MP, Waldman EA. Eventos Adversos pós vacina contra a difteria, coqueluche e tétano e fatores associados à sua gravidade. Rev Saude Publica. 2007; 41: 1032-41.

13.Fassarella CS, Santos CV, Rosa LS. A resposta do profissional de enfermagem na aplicação da vacina BCG sob óptica da segurança do paciente. Rev Rede de Cuidados em Saude. 2013; 7: 1-10 .

14.Ministério da Saúde (Br). Informe Técnico da Vacina Inativada Poliomielite (VIP). Brasília (DF): Editora MS; 2012.

15.Secretaria do Estado de São Paulo. Vacina contra o rotavírus. Rev Saude Publica. 2006; 40: 355-8.

16.Carvalho ALA, Oliveira DLA, Pereira W, Souza FGM. Hospitalização como oportunidade para atualizar o calendário básico de vacinação: uma experiência realizada no hospital universitário em São Luis- MA. Rev RENE. 2004; 5:89-94.

17.Ministério da Saúde (Br) Informe Técnico Campanha Nacional de Vacinação contra a Influenza. Brasília (DF): Editora MS; 2014.

18.Ferrarini MAG, Scattolin MAA, Rodrigues MM, Resende MHF, Santos ICLS, Iazzetti AV. Síndrome de Guillain - Barré em associação temporal com a vacina Influenza A. Rev Paul Pedritr. 2011; 29:685-8. 